\title{
An endophytic Schizophyllum commune Fr. exhibits in-vitro and in-vivo antidiabetic activity in streptozotocin induced diabetic rats
}

\author{
Avinash Sharma ${ }^{1}$, Rajvir Kaur ${ }^{1}$, Jasleen Kaur ${ }^{1}$, Saweta Garg ${ }^{2}$, Rajbir Bhatti ${ }^{2}$ and Amarjeet Kaur ${ }^{1 *}$
}

\begin{abstract}
The present study aimed at isolation of endophytic basidiomycetous fungi and evaluation of their in-vitro and in-vivo antidiabetic potential. Preliminary screening for in-vitro activity was carried out using a-glucosidase inhibition assay. An endophytic isolate Sch1 (isolated from Aloe vera), identified to be Schizophyllum commune Fr. on molecular basis, exhibiting more than $90 \%$ a-glucosidase inhibitiory activity was selected for further studies. Detailed in-vivo investigations for antidiabetic potential of ethyl acetate extract of S. commune (Sch1), at two different doses, were carried out in streptozotocin induced diabetic Wistar rats. Treatment of diabetic rats with S. commune extract caused significant decrease in blood glucose level and increase in body weight after 14 days experimental period. It significantly restored renal parameters including creatinine, blood urea nitrogen, fractional excretion of sodium, and potassium level in diabetic rats. Improvement in lipid profile and level of antioxidant parameters viz. reduced glutathione, thiobarbituric acid reactive species, and superoxide anion generation was also observed after treatment. Liver enzymes (serum glutamic pyruvic transaminase, serum glutamic-oxaloacetic transaminases, and alkaline phosphatase) homeostasis was found to be markedly improved in diabetic rats administered with S. commune extract. The effects were more pronounced at higher concentration and comparable to acarbose which was used as positive control. Phytochemical analysis revealed the presence of phenolics and terpenoids in the ethyl acetate extract. This is the first report highlighting the therapeutic potential of an endophytic S. commune in the management of diabetes.
\end{abstract}

Keywords: Schizophyllum commune, Basidiomycetes, a-Glucosidase inhibition, Antidiabetic

\section{Introduction}

Endophytes are microorganisms that reside within the living plant tissues for a variable period of their life without causing any symptomatic infection (Petrini 1991). Recently they have become the focus of attraction as a potent group of microorganisms able to synthesize diverse group of bioactive compounds. Various compounds derived from the endophytic fungi are known to exhibit a wide range of bioactivities like anticancer, antiviral, antidiabetic, antioxidant, immunomodulatory,

\footnotetext{
${ }^{*}$ Correspondence: amarjeet_b@rediffmail.com

${ }^{1}$ Department of Microbiology, Guru Nanak Dev University, Amritsar,

Punjab 143005, India

Full list of author information is available at the end of the article
}

antiparasitic, and antimicrobial (Strobel and Daisy 2003; Kaul et al. 2012; Kaur et al. 2020). A survey of literature revealed that majority of the bioactive compounds have been isolated from endophytic fungi belonging to the phylum Ascomycota. Endophytic basidiomycetes, despite their prodigious potential to produce bioactive molecules with application in various fields ranging from medicinal, agricultural, and industrial (Waller et al. 2005; Puri et al. 2006; Katoch et al. 2017), have not received much attention due to sampling biases. There are several reasons which restrict the detection of endophytic basidiomycetes with conventional culture-based method viz. slow growth and lack of knowledge about their morphological characters (Martin et al. 2015). Keeping in view their unexplored potential, we have attempted to 
isolate basidiomyceteous fungi from different plants and screened them for their bioactive potential. This study deals with the antidiabetic potential of endophytic basidiomycetes.

Diabetes mellitus, a group of metabolic disorders associated with elevated blood glucose level due to lack of insulin secretion, insulin resistance, or both, has emerged as a major health problem. It is statistically estimated that about 693 million people in the world are going to suffer from diabetes mellitus till 2045 (Cho et al. 2018). Diabetes mellitus results in severe complications such as neuropathy, nephropathy, retinopathy, and cardiovascular diseases (Clements and Bell 1985). Postprandial hyperglycemia is mainly responsible for the majority of the diabetes related complications (Gavin 2001; Ceriello 2005). Commercially available drugs used for the treatment of diabetes suffer from certain limitations and have side effects (Chaudhury et al. 2017), necessitating the need for novel and more effective antidiabetic agents from natural sources. One of the therapeutic approaches approved for the management of diabetes mellitus is the use of $\alpha$-glucosidase inhibitors. By virtue of their ability to modulate the activity of carbohydrate hydrolysing enzymes, $\alpha$-glucosidase inhibitors can help to control post-prandial hyperglycemia. In the present work, endophytic basidiomycetes were isolated and preliminary screening for their antidiabetic potential was conducted using in-vitro $\alpha$-glucosidase inhibitory assay. After screening an endophytic culture, identified to be Schizophyllum commune Fr., possessing high in-vitro $\alpha$-glucosidase inhibitory activity was selected and evaluated for its in-vivo antidiabetic effect in streptozotocin (STZ) induced diabetic rats.

\section{Materials and methods}

\section{Isolation of endophytic fungi}

Isolation of endophytic fungi was carried out from different healthy asymptomatic plants viz. Aegle marmelos (L.) Corr., Cordia myxa L., Phyllanthus emblica L., Lawsonia inermis L., Ficus virens Ait., Ocimum tenuiflorum L., and Aloe vera (L.) Burm.f.. Plant parts were thoroughly washed with tap water to remove dirt and solid particles. Surface sterilization was performed with $70 \%$ ethanol for 1-2 min, followed by $4 \%$ sodium hypochlorite exposure for 3-4 $\mathrm{min}$, and subsequently washed with sterile distilled water. To ensure surface sterilization, the water obtained after last wash was plated on potato dextrose agar (PDA) (Himedia, Mumbai, India) plates. Surface sterilized plant parts were cut into small pieces $(3-5 \mathrm{~mm}$ size) and placed on isolation medium containing malt extract $(15 \mathrm{~g} / \mathrm{l})$, benomyl $(50 \mathrm{mg} / \mathrm{l})$, chloramphenicol $(100 \mathrm{mg} / \mathrm{l})$, streptomycin sulphate $(100 \mathrm{mg} / \mathrm{l})$, and agar $(20 \mathrm{~g} / \mathrm{l})($ Oses et al. 2008). The plates were incubated at
$30{ }^{\circ} \mathrm{C}$ for $5-10$ days and the emerging fungal mycelia were purified and preserved on PDA plates.

\section{Production}

Purified endophytic fungal cultures were grown on PDA plates, and one mycelial agar plug $(8 \mathrm{~mm})$ from the periphery of the growing fungal cultures was inoculated in Erlenmeyer flasks $(250 \mathrm{ml})$ containing $50 \mathrm{ml}$ malt extract broth (malt extract 2\%, dextrose $2 \%$, peptone $0.1 \%$ ). The flasks were incubated at $30{ }^{\circ} \mathrm{C}$ for 10 days in a rotary shaker at $180 \mathrm{rpm}$. After incubation, $50 \mathrm{ml}$ ethyl acetate was added to each flask and extraction of metabolites was carried out at $40{ }^{\circ} \mathrm{C}$ for $1.5 \mathrm{~h}$ twice at $120 \mathrm{rpm}$. Thereafter, the upper organic phase was collected and concentrated to dryness by using rotary evaporator (BUCHI). The concentrated sample was then re-suspended in phosphate buffer saline $(\mathrm{pH}$ 7.4) for further use.

\section{a-Glucosidase inhibitory (AGI) assay}

AGI assay was conducted using $p$-nitrophenyl-alphaD-glucopyranoside (p-NPG) (Himedia, Mumbai, India) as substrate (Singh and Kaur 2016). In a 96 well plate, reaction mixture containing $50 \mu \mathrm{l}$ phosphate buffer (50 mM, pH 6.8), $10 \mu \mathrm{l} \alpha$-glucosidase $(1 \mathrm{U} / \mathrm{ml}$ ) (Himedia, Mumbai, India), and $20 \mu \mathrm{l}$ extract was preincubated at $37^{\circ} \mathrm{C}$ for five min. $20 \mu \mathrm{l}$-NPG $(2 \mathrm{mM})$ was added as substrate and incubated further at $37^{\circ} \mathrm{C}$ for $30 \mathrm{~min}$. The reaction was terminated by adding $50 \mu \mathrm{l} \mathrm{Na}_{2} \mathrm{CO}_{3}(0.1 \mathrm{M})$. The end product of the reaction, $p$-nitrophenol formed after hydrolysis of p-NPG by $\alpha$-glucosidase, was quantified by measuring the absorbance at $405 \mathrm{~nm}$. Each experiment was performed in triplicates. Acarbose was used as a positive control. The results are expressed as percentage inhibition, which was calculated using the formula:

$$
\% \text { inhibition }=\frac{\mathrm{Ac}-\mathrm{As}}{\mathrm{Ac}} \times 100
$$

where $A_{c}$ was the absorbance of control, and $A_{s}$ was the absorbance of the sample.

\section{Identification of fungal culture}

The culture was identified on molecular basis by amplification of ITS1-5.8S-ITS2rDNA region by National Centre for Microbial Resource (NCMR) Pune, India. Phylogenetic analysis was performed using MEGA-X software. Multiple sequence alignment of NCBI downloaded sequences was performed using clustalW software. Phylogenetic tree was constructed using "neighbor-joining" statistical method with bootstrap method for the test of phylogeny, considering 1000 number of bootstrap replications and Maximum Composite Likelihood as a substitution model. 
The morphology of the selected isolate was observed under light microscope (Olympus). To determine the number of nuclei in per compartment of hyphae the fungal mycelium stained with 4',6-diamidino-2-phenylindole (DAPI) $(10 \mu \mathrm{g} / \mathrm{ml})$ and observed under fluorescent microscope (Nikon ECLIPSE Ts2).

\section{Phytochemical tests}

The fungal extract was subjected to various tests to determine the presence of different phytochemicals. $20 \mu \mathrm{l}$ fungal extract was spotted on TLC silica gel and sprayed with different visualization reagents for the detection of alkaloids, phenolics, and amines. Dragendorff reagent was used to detect the presence of alkaloids. Detection of phenolics was carried out by spraying with Fast blue B (3,3-dimethoxybiphenyl-4, 4-bis(diazonium)-dichloride) and ferric chloride. Amines were detected using ninhydrin reagent. Terpenoids were determined by dissolving fungal extract in chloroform followed by addition of concentrated sulphuric acid (Waksmundzka et al. 2008; Batool et al. 2019).

\section{In-vivo studies \\ Animals}

Wistar albino rats aged between 8 and 10 weeks (170200 g) were purchased from National Institute of Pharmaceutical Education and Research (NIPER), Mohali. Animal experiment protocol (226/CPCSEA 2017/03) was duly approved by Institutional Animal Ethics Committee (IAEC) of Guru Nanak Dev University, Amritsar, Punjab (India). All the experiments were conducted in accordance with the guidelines established by Committee for the Purpose of Control and Supervision of Experiments on Animals (CPCSEA), Ministry of Environment, Forests and Climate Change, Government of India. Wistar albino rats were housed in polypropylene cages under standard laboratory conditions of $23-25^{\circ} \mathrm{C}$ temperature with $12 \mathrm{~h}$ light-dark cycle and fed with standard pellet diet and water in the Animal House of Guru Nanak Dev University, Amritsar.

\section{Experimental design}

A total of 25 Wistar albino rats were randomly divided into five groups with five rats each: normal healthy control group (NC), diabetic rats administered with STZ (Sigma-Aldrich, St. Louis, USA) (DC), diabetic rats treated with $60 \mathrm{mg} / \mathrm{kg}$ body weight of reference compound acarbose (SRL Pvt. Limited, India) (PC), diabetic rats treated with $50 \mathrm{mg} / \mathrm{kg}$ body weight (SC50) and $100 \mathrm{mg} / \mathrm{kg}$ body weight (SC100) of S. commune extract.

\section{Induction of experimental diabetes}

After 15 days acclimatization of rats, a freshly prepared dose of STZ (45 mg/kg body weight) in $0.02 \mathrm{M}$ citrate buffer ( $\mathrm{pH} 4.5)$ was injected intraperitoneally to induce diabetes. To prevent the lethal effect of STZ induced hypoglycaemia, rats were administrated with $5 \%$ dextrose solution after STZ injection. On 4th day blood was drawn from tail tip, rats with blood glucose level higher than $400 \mathrm{mg} / \mathrm{dl}$ were considered diabetic and used for further study.

\section{Biochemical evaluation}

From 4th day onwards oral administration of S. commune extract (SC50 and SC100) and standard drug acarbose was done at a fixed time (between 10:00 and 11:00 AM) till the 14th day. Blood sample for the determination of glucose level at 0,4 th, and 7 th day was withdrawn from tail tip before the administration of $S$. commune extract, and blood glucose level was estimated by using electronic glucometer. At the end of experimental period, blood was drawn by retro orbital puncture from anaesthetized rats. Body weight of experimental animals was also recorded on 0,4 th, 7th, and 14th day. After 14 days experimental phase, rats were anaesthetized by intraperitoneal injection of ketamine $(50 \mathrm{mg} / \mathrm{kg})$. Blood samples were withdrawn by retro orbital puncture under anaesthesia before the rats were sacrificed by cervical dislocation. Serum samples were collected by centrifugation of blood and were used to estimate the level of creatinine, blood urea nitrogen (BUN), fractional excretion of sodium (FeNa), potassium, serum glutamic pyruvic transaminase (SGPT), serum glutamic-oxaloacetic transaminase (SGOT) and alkaline phosphatase (ALP). The quantification of lipid profile was also done in serum. Kidney and liver from all groups of rats were removed and washed with $1.17 \%$ potassium chloride $(\mathrm{KCl})$ solution. A small part of both tissues was used to estimate SAG and the remaining section was minced and homogenized (10\% $\mathrm{w} / \mathrm{v}$ ) in $1.17 \% \mathrm{KCl}$ solution by teflon homogenizer. The homogenates of both tissues (kidney and liver) were centrifuged for $10 \mathrm{~min}$ at $3000 \mathrm{~g}$. The supernatant was collected and used for the estimation of oxidative stress parameters viz. reduced glutathione (GSH) level and thiobarbituric acid reactive substances (TBARS) level.

\section{Determination of serum lipid profile}

Lipid profile consists of total cholesterol (TC), triglycerides (TG), high density lipoprotein (HDL), and low-density lipoprotein (LDL). Assessment of TC, TG, and HDL was done by commercially available kits using chemistry analyser (BeneSphera, USA). The level of LDL in serum sample was determined by using traditional Friedewald 
formula as described by Warnick et al. (1990). In this method, the calculated values of TC, HDL, and TG were used to determine the value of LDL.

$$
\mathrm{LDL}=\mathrm{TC}-\mathrm{HDL}-(\mathrm{TG} / 5) .
$$

\section{Renal and liver function tests}

Estimation of renal (creatinine, BUN, FeNa, and potassium) and liver (SGPT, SGOT, and ALP) function parameters in serum sample was also performed by commercially available kits using clinical chemistry analyser.

\section{Determination of oxidative stress parameters in kidney and liver \\ Determination of GSH}

The level of GSH in tissue was estimated by the method described by Beutler et al. (1963). Trichloroacetic acid $(10 \% \mathrm{w} / \mathrm{v})$ was mixed with tissue homogenate supernatant in 1:1 ratio. Reaction mixture was centrifuged at $12,000 \mathrm{~g}$ for $10 \mathrm{~min}$ at $4{ }^{\circ} \mathrm{C}$. Resultant supernatant $(0.5 \mathrm{ml})$ was mixed with $2 \mathrm{ml}$ disodium hydrogen phosphate $(0.3 \mathrm{M})$. Thereafter, $0.25 \mathrm{ml}(0.001 \mathrm{M})$ of 5,5-dithio-bis(2-nitro benzoic acid) (DTNB) (Loba Chemie, India) was added and absorbance was measured by spectrophotometer at $412 \mathrm{~nm}$. DTNB was freshly prepared in 1\% citric acid. Reduced glutathione $(10-100 \mu \mathrm{M})$ was used as reference standard. Results were expressed as micromoles of reduced glutathione per $\mathrm{mg}$ of protein.

\section{Determination of TBARS}

Lipid peroxidation in tissue results in TBARS. Quantitative measurement of TBARS was done as described by Niehaus and Samuelsson (1968). Under acidic conditions, malondialdehyde and other TBARS react with thiobarbituric acid to form a pink coloured chromophore, measured spectrophotometrically at $535 \mathrm{~nm}$. In this method freshly prepared trichloroacetic acid (15\%), hydrochloric acid $(0.25 \mathrm{~N})$, and thiobarbituric acid $(0.375 \%)$ in the ratio of 1:1:1 were prepared. $1 \mathrm{ml}$ of tissue homogenate was mixed thoroughly with $2 \mathrm{ml}$ of trichloroacetic acidhydrochloric acid-thiobarbituric acid reagent. The reaction mixture was kept in water bath at $100{ }^{\circ} \mathrm{C}$ for $15 \mathrm{~min}$ and centrifuged at $10,000 \mathrm{~g}$ for $10 \mathrm{~min}$. Colour in the reaction tubes was measured at $535 \mathrm{~nm}$ against reagent blank. 1,1,3,3- tetra methoxy propane (1-10 nM) was used as reference standard.

\section{Determination of SAG}

The method described by Wang et al. (1998) was used to determine the SAG in tissue. Phosphate buffered saline $(5 \mathrm{ml})$ containing $100 \mu \mathrm{M}$ of nitro blue tetrazolium chloride (NBT) (Loba Chemie, India) was inoculated with $25 \mathrm{mg}$ tissue and incubated at $37{ }^{\circ} \mathrm{C}$ for $90 \mathrm{~min}$. After incubation reduction of NBT in the reaction was stopped by adding five $\mathrm{ml} \mathrm{HCl}(0.5 \mathrm{M})$ followed by homogenization in $1 \mathrm{ml}$ cocktail of $0.1 \mathrm{M}$ sodium hydroxide, $0.1 \%$ sodium lauryl sulphate, and $40 \mathrm{mg} / \mathrm{l}$ diethylenetriaminepentaacetic acid. Centrifugation of the resulted mixture was done at $20,000 \mathrm{~g}$ for $20 \mathrm{~min}$. Pellet formed after centrifugation was dissolved in $1.5 \mathrm{ml}$ pyridine and incubated at $80{ }^{\circ} \mathrm{C}$ for $90 \mathrm{~min}$ to extract formazan which formed after reaction of NBT with superoxide anions. Centrifugation was performed at $10,000 \mathrm{~g}$ for $10 \mathrm{~min}$. The absorbance of formazan was measured at $540 \mathrm{~nm}$. Calculation of reduced NBT was performed by using following formula:

$$
\text { amount of reduced NBT }=\frac{\mathrm{A} \times \mathrm{V}}{\mathrm{T} \times \mathrm{W} \times \varepsilon \times l}
$$

where, $\mathrm{A}$ is absorbance, $\mathrm{V}$ is volume of pyridine, $\mathrm{T}$ is time for which the tissue was incubated with NBT, W is the weight of tissue used, $\varepsilon$ is extinction coefficient and $l$ is length of light path.

\section{Statistical analysis}

All results were expressed as mean \pm standard deviation. Statistical analysis was performed by using Graphpad prism software version 7.0. The significant difference within the groups was calculated by using oneway ANOVA, followed by Tukey's multiple comparisons test. Results with $\mathrm{P}<0.05$ were considered as statistically significant. IC50 values were calculated by using probit analysis.

\section{Results}

\section{Isolation and identification of endophytic fungi}

In this study, an attempt was made to isolate endophytic basidiomycetes on medium supplemented with benomyl. Seventy three fungal cultures were isolated from different asymptomatic healthy plants and screened for their AGI activity. Forty fungal isolates were found to exhibit negligible (less than 20\%) AGI activity, whereas 29 isolates showed inhibitory activity in the range of 40-60\%. Good inhibitory activity above $80 \%$ was demonstrated by four endophytic cultures T1b, B2b, Sch1, and M1a isolated from Ocimum tenuiflorum, Aegle marmelos, Aloe vera, Lawsonia inermis respectively. The $\mathrm{IC}_{50}$ values of these cultures were also determined (Table 1). Morphological analysis revealed T1b, B2b, and M1a as species of Alternaria. Sch1 a non-sporulating mycelial culture was identified to be Schizophyllum commune on molecular basis by amplification of the ITS1-5.8S-ITS2 rDNA region. The isolate Sch1 was selected for further study. It exhibited more than $90 \%$ AGI activity with $\mathrm{IC}_{50}$ value of $425 \mu \mathrm{g} / \mathrm{ml}$. The culture produced white coloured colonies on PDA plates reaching a diameter of $7.2 \mathrm{~cm}$ after 
Table $1 \quad I_{50}$ values of endophytic isolates possessing high (> 80\%) AGl activity

\begin{tabular}{lll}
\hline Endophytic isolate & Host plant & $I_{50}(\mu \mathrm{g} / \mathrm{ml})$ \\
\hline T1b & Ocimum tenuiflorum & 630 \\
B2b & Aegle marmelos & 763 \\
Sch1 & Aloevera & 425 \\
M1a & Lawsonia inermis & 582 \\
Acarbose & - & 76.6 \\
\hline
\end{tabular}

six days of incubation at $30{ }^{\circ} \mathrm{C}$ (Fig. 1a). Hyphae were septate and profusely branched (Fig. 1b). After staining with DAPI, the hyphae were found to be dikaryotic as two nuclei in a single compartment were observed under fluorescent microscope (Fig. 1c). A sequence of 564 bps was obtained which on alignment with homologous nucleotide sequences revealed 100\% similarity with Schizophyllum commune. The amplified ITS1-5.8S rDNA-ITS2 sequence has been submitted to GenBank under the accession number MN475198. On account of the observed morphological and molecular characteristics, strain Sch1 could be identified to be Schizophyllum commune (Fig. 1d). The isolate Schizophyllum commune Fr. (Sch1) has been deposited vide accession number NFCCI 4838 in National Fungal Culture Collection of India (NFCCI), Agharkar Research Institute, Pune, India.

\section{Effect of S. commune extract in STZ induced diabetic rats}

As the isolate S. commune (Sch1) exhibited in-vitro antidiabetic effect, in-vivo antidiabetic studies were conducted in STZ induced diabetic rats.

\section{Hypoglycemic effect of S. commune extract}

After the induction of diabetes in rats by intraperitoneal injection of STZ, the blood glucose level in experimental animals was significantly $(\mathrm{P}<0.05)$ increased from the basal level as compared to the normal healthy control group. The level of blood glucose was found to be $597 \pm 49.80 \mathrm{mg} / \mathrm{dl}$ in the diabetic control group at the end of the experimental period. A gradual decrease in the blood glucose level over time was recorded in diabetic rats treated with $S$. commune extract. At the end
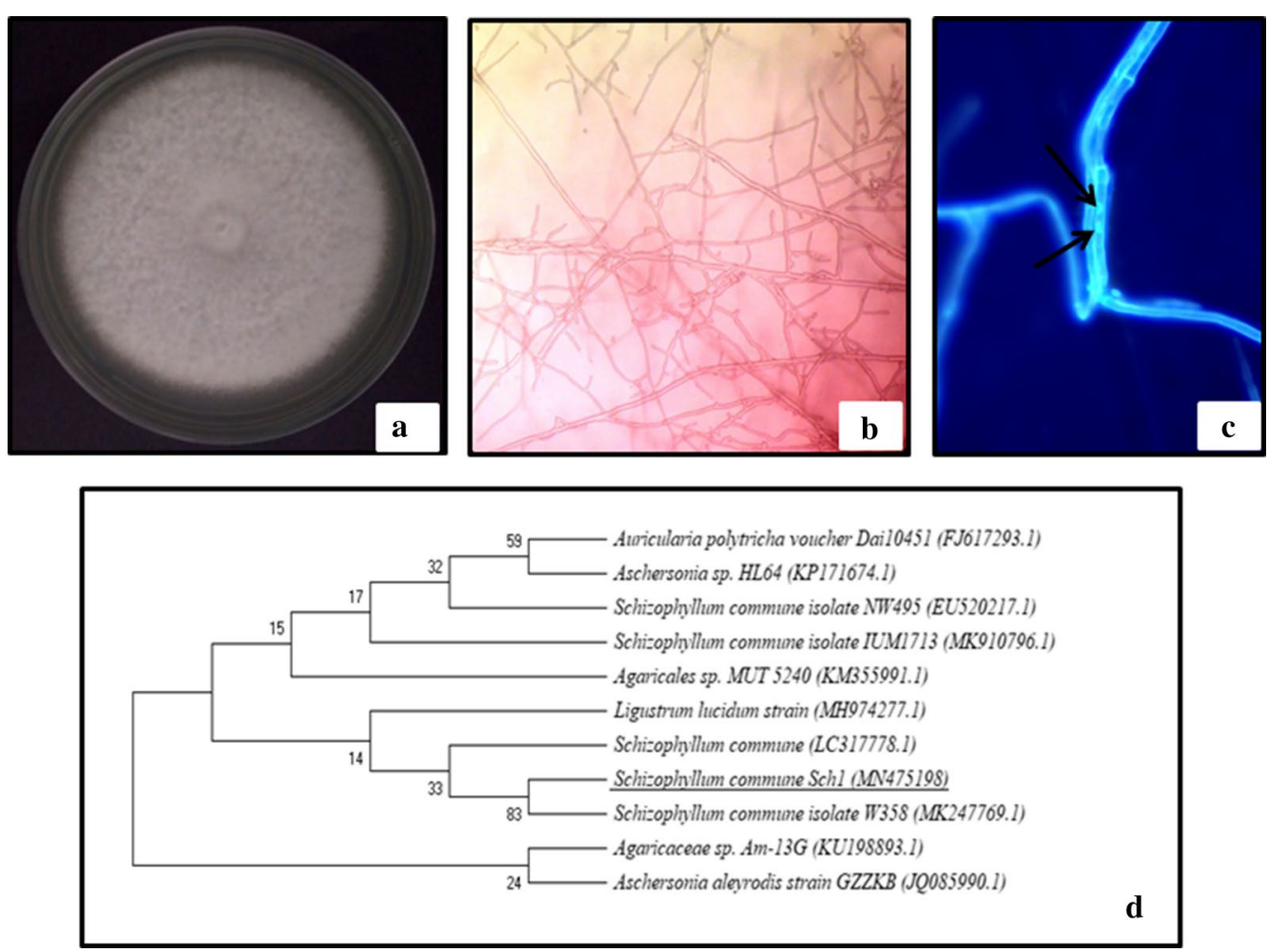

Fig.1 S. commune (Sch1) a colony morphology on PDA. b microscopic view (40X) c hyphae stained with DAPI under fluorescent microscope (100X). d ITS1-5.8S rDNA-ITS2 gene sequence based phylogenetic tree showing the taxonomic position of S. commune (Sch1). Phylogenetic analysis consisted of 11 nucleotide sequences. The evolutionary history was inferred using the Neighbor-Joining method. The optimal tree with the sum of branch length 1.58935111 is shown. All ambiguous positions were removed for each sequence pair. There were a total of 649 positions in the final dataset. Evolutionary analyses were conducted in MEGA X 
of the experiment, blood glucose level decreased significantly $(\mathrm{P}<0.05)$ by $51 \%(292.2 \pm 63.93 \mathrm{mg} / \mathrm{dl})$ and $56 \%$ $(259.78 \pm 28.38 \mathrm{mg} / \mathrm{dl})$ after treatment with $50 \mathrm{mg} / \mathrm{kg}$ and $100 \mathrm{mg} / \mathrm{kg}$ S. commune extract, respectively, as compared to the untreated diabetic control group (Fig. 2a). The effect of $S$. commune extract was comparable to standard drug acarbose, where 63\% decrease in blood glucose level was recorded after 14 days experimental period.

\section{Effect of S. commune extract on body weight of diabetic}

\section{rats}

All STZ induced untreated diabetic rats manifested a significant $(\mathrm{P}<0.05)$ loss of body weight when compared with the normal control group at the end of the experiment. The higher dose of $S$. commune extract was recorded to be more effective as significant $(\mathrm{P}<0.05)$ gain of body weight after 14 days of treatment was documented when compared to the diabetic control group (Fig. 2b).

\section{Effect of S. commune extract on serum lipid profile}

In diabetic rats, the levels of TC, LDL, and TG increased $(\mathrm{P}<0.05)$, whereas HDL level decreased $(\mathrm{P}<0.05)$ after 14 days as compared to normal healthy control. Treatment with $S$. commune extracts significantly $(\mathrm{P}<0.05)$ improved the lipid profile in STZ induced diabetic rats (Fig. 2c). The effect was more pronounced at higher concentration (SC100) where the level of TC, TG, and LDL were decreased significantly $(\mathrm{P}<0.05)$ by $63 \%, 28 \%, 80 \%$ respectively, whereas a significant increase of $78 \%$ in HDL level was observed as compared to the diabetic control group.

\section{Effect of S. commune extract on renal parameters}

The present study considered the level of creatinine, BUN, potassium, and $\mathrm{FeNa}$ to measure the performance of the kidney. In STZ-induced diabetic rats, the level of these parameters was increased $(\mathrm{P}<0.05)$ when compared with the normal control group. Although treatment with both SC50 and SC100 significantly $(\mathrm{P}<0.05)$ reduced the level of creatinine, BUN, potassium, and $\mathrm{FeNa}$ as compared to the diabetic control group, the results were more pronounced at higher concentration of the extract. As evident in Table 2, the reduction obtained was also comparable with the positive and normal control group.
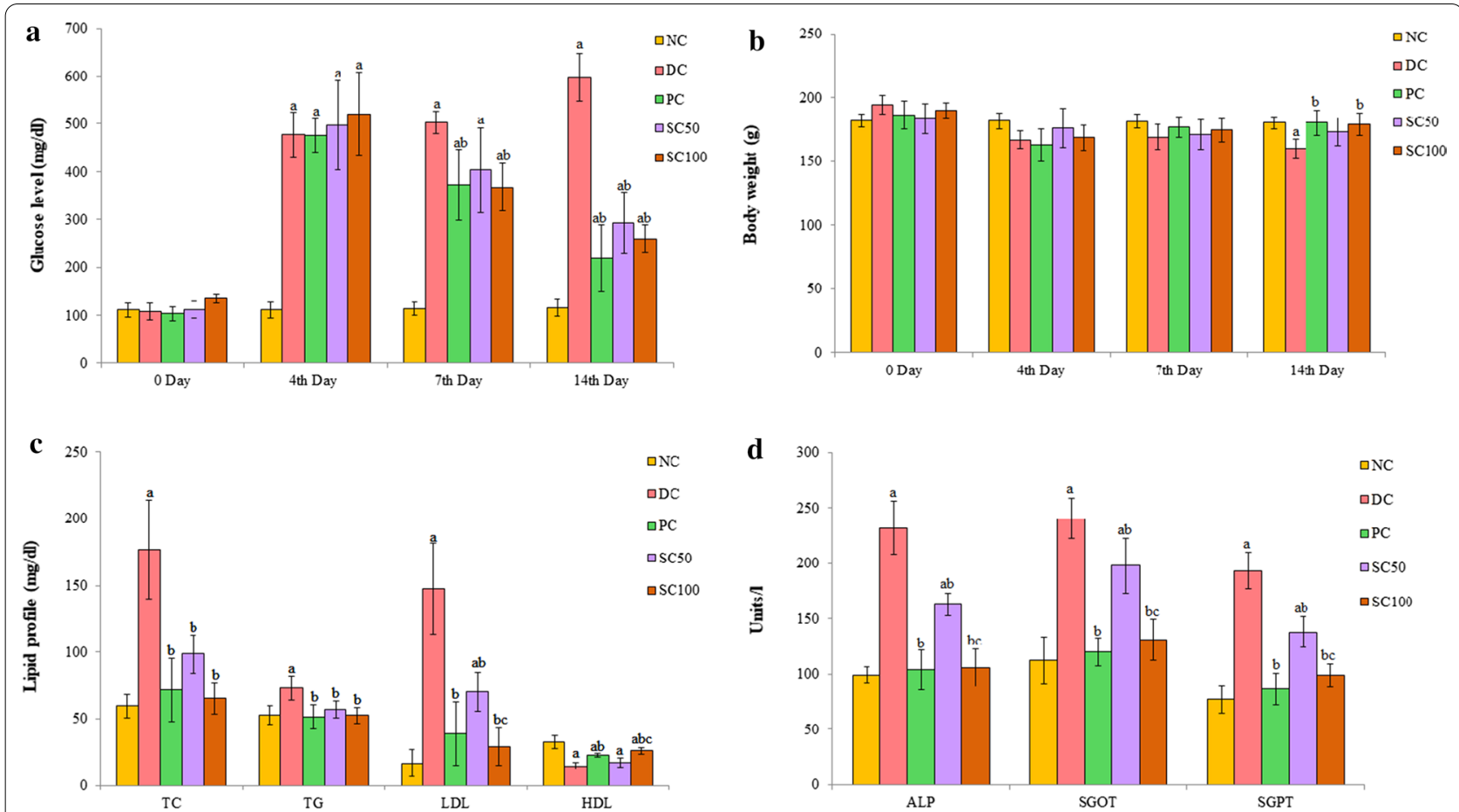

Fig.2 Effect of S. commune extract on a blood glucose level; $\mathbf{b}$ body weight; $\mathbf{c}$ lipid profile; $\mathbf{d}$ liver biochemical parameters in STZ induced diabetic rats. Data are expressed as mean \pm S.D. $(n=5)$. NC: normal healthy control; DC: diabetic control; PC: positive control (STZ induced diabetic rats treated with reference drug acarbose ( $60 \mathrm{mg} / \mathrm{kg}$ body weight)); SC50 and SC100: STZ induced diabetic rats treated with S. commune extract (50 and $100 \mathrm{mg} / \mathrm{kg}$ body weight respectively). ${ }^{\mathrm{a}} \mathrm{P}<0.05$ Different control groups when compared with normal group. ${ }^{\mathrm{b}} \mathrm{P}<0.05$ Diabetic control group when compared with other treated groups. ${ }^{c} P<0.05 \mathrm{~S}$. commune extract treated groups when compared with each other 
Table 2 Effect of S. commune extract on creatinine, BUN, FeNa, and potassium level in STZ induced diabetic rats

\begin{tabular}{|c|c|c|c|c|}
\hline Groups & Creatinine $(\mathrm{mg} / \mathrm{dl})$ & BUN (mg/dl) & FeNa (\%) & Potassium (mmol) \\
\hline NC & $0.756 \pm 0.107$ & $39.52 \pm 9.123$ & $3.214 \pm 0.545$ & $4.856 \pm 1.374$ \\
\hline DC & $1.77 \pm 0.165^{\mathrm{a}}$ & $91.71 \pm 12.781^{\mathrm{a}}$ & $12.716 \pm 2.847^{\mathrm{a}}$ & $11.374 \pm 2.304^{\mathrm{a}}$ \\
\hline PC & $0.852 \pm 0.172^{b}$ & $50.656 \pm 6.577^{b}$ & $5.513 \pm 1.016^{b}$ & $4.264 \pm 1.299^{b}$ \\
\hline SC50 & $1.188 \pm 0.133^{\mathrm{a}, \mathrm{b}}$ & $69.666 \pm 4.302^{a, b}$ & $7.588 \pm 0.776^{a, b}$ & $8.054 \pm 1.006^{a, b}$ \\
\hline SC100 & $0.872 \pm 0.092^{b, c}$ & $51.444 \pm 2.374^{\mathrm{b}, \mathrm{c}}$ & $5.226 \pm 1.246^{b}$ & $4.528 \pm 0.482^{b, c}$ \\
\hline
\end{tabular}

Data are expressed as mean \pm S.D. $(n=5)$. NC: normal healthy control; DC: diabetic control; PC: positive control (STZ induced diabetic rats treated with reference drug acarbose ( $60 \mathrm{mg} / \mathrm{kg}$ body weight)); SC50 and SC100: STZ induced diabetic rats treated with S. commune extract (50 and $100 \mathrm{mg} / \mathrm{kg}$ body weight respectively)

a $\mathrm{P}<0.05$ Different control groups when compared with normal group

b $\mathrm{P}<0.05$ Diabetic control group when compared with other treated groups

c $\mathrm{P}<0.05$ S. commune extract treated groups when compared with each other

Effect of S. commune extract on oxidative stress parameters Table 3 clearly displays the effect of $S$. commune extract on oxidative stress parameters. In this study, a significantly decreased level of GSH along with significantly increased levels of TBARS and SAG in kidney and liver of diabetic control were recorded. The imbalanced level of these oxidative stress markers was improved after treatment with $S$. commune extract. Treatment with higher concentration of S. commune extract (SC100) enhanced the GSH level in kidney and liver to 9.556 and $8.104 \mu \mathrm{mol} / \mathrm{mg}$ protein respectively, which in diabetic rats was observed to be 4.720 and $4.018 \mu \mathrm{mol} / \mathrm{mg}$ protein respectively. The levels of TBARS and SAG in the liver and kidney were also significantly $(\mathrm{P}<0.05)$ reduced in diabetic rats treated with SC50 and SC100 as compared to untreated diabetic control.

Effect of S. commune extract on liver function parameters In the diabetic control group, the level of ALP, SGOT, and SGPT increased $(\mathrm{P}<0.05)$ as compared to the normal healthy control. Diabetic rats treated with $S$. commune extract evinced significant $(\mathrm{P}<0.05)$ reduction in the level of SGOT, SGPT, and ALP after 14 days of treatment.
As evident from the results (Fig. 2, Tables 2, 3) both the concentrations showed improvement in the observed biochemical parameters. Dose dependent effects were also observed for the majority of the parameters viz. LDL, HDL, ALP, SGOT, SGPT, creatinine, BUN, potassium, GSH, SAG, TBARS (kidney). In case of TG, TC, FeNa, TBARS (liver) comparable improvement was obtained with both the doses.

An attempt to determine the nature of the compounds present in the extract was also made by using phytochemical analysis. S. commune extract was found to contain phenolic and terpenoid compounds. Presence of the phenols was indicated by the appearance of brownreddish violet colour in fast blue $B$ test and confirmed by the formation of violet colour in ferric chloride test, while for terpenoids an intense reddish-brown colour was developed at the interface when sulphuric acid was added in chloroform dissolved fungal extract. Lack of development of orange brown colour on spraying with dragendorff reagent indicated the absence of alkaloids. The absence of amines was also determined as no pink or purple colour spots were obtained when sprayed with ninhydrin.

Table 3 Effect of S. commune extract on oxidative stress parameters in STZ induced diabetic rats

\begin{tabular}{|c|c|c|c|c|c|c|}
\hline Groups & $\begin{array}{l}\text { GSH Kidney ( } \mu \text { mol/ } \\
\text { mg protein) }\end{array}$ & $\begin{array}{l}\text { GSH Liver ( } \mu \mathrm{mol} / \mathrm{mg} \\
\text { protein) }\end{array}$ & $\begin{array}{l}\text { TBARS Kidney } \\
\text { (nmol/mg protein) }\end{array}$ & $\begin{array}{l}\text { TBARS Liver (nmol/ } \\
\text { mg protein) }\end{array}$ & $\begin{array}{l}\text { SAG Kidney (pmol/ } \\
\mathrm{min} / \mathrm{mg} \text { tissue) }\end{array}$ & $\begin{array}{l}\text { SAG Liver (pmol/ } \\
\mathrm{min} / \mathrm{mg} \text { tissue) }\end{array}$ \\
\hline $\mathrm{NC}$ & $11.01 \pm 1.620$ & $9.24 \pm 1.088$ & $0.398 \pm 0.103$ & $0.624 \pm 0.128$ & $5.04 \pm 0.823$ & $4.78 \pm 1.304$ \\
\hline $\mathrm{DC}$ & $4.720 \pm 0.486^{a}$ & $4.018 \pm 0.623^{a}$ & $1.766 \pm 0.296^{a}$ & $1.628 \pm 0.378^{a}$ & $18.612 \pm 1.868^{a}$ & $17.512 \pm 1.571^{a}$ \\
\hline PC & $11.892 \pm 1.880^{\mathrm{b}}$ & $8.168 \pm 1.864^{b}$ & $0.532 \pm 0.127^{b}$ & $0.602 \pm 0.057^{b}$ & $6.19 \pm 0.862^{b}$ & $7.228 \pm 0.640^{a, b}$ \\
\hline SC 50 & $6.862 \pm 0.768^{\mathrm{a}}$ & $5.092 \pm 0.690^{a}$ & $1.118 \pm 0.103^{a, b}$ & $1.038 \pm 0.082^{a, b}$ & $13.104 \pm 1.159^{a, b}$ & $12.832 \pm 1.007^{a, b}$ \\
\hline SC100 & $9.556 \pm 1.032^{b, c}$ & $8.104 \pm 1.647^{b, c}$ & $0.604 \pm 0.105^{b, c}$ & $0.732 \pm 0.084^{b}$ & $10.21 \pm 1.239^{a, b, c}$ & $10.216 \pm 0.746^{\mathrm{a}, \mathrm{bc}}$ \\
\hline
\end{tabular}

Data are expressed as mean \pm S.D. $(n=5)$. NC: normal healthy control; DC: diabetic control; PC: positive control (STZ induced diabetic rats treated with reference drug acarbose ( $60 \mathrm{mg} / \mathrm{kg}$ body weight)); SC50 and SC100: STZ induced diabetic rats treated with S. commune extract (50 and $100 \mathrm{mg} / \mathrm{kg}$ body weight respectively)

a $\mathrm{P}<0.05$ Different control groups when compared with normal group

b $\mathrm{P}<0.05$ Diabetic control group when compared with other treated groups

c $\mathrm{P}<0.05$ S. commune extract treated groups when compared with each other 


\section{Discussion}

The present study aimed at the isolation of endophytic basidiomycetes and evaluation of their antidiabetic potential. A survey of literature revealed that, despite their potential as a natural source of bioactive metabolites, endophytic basidiomycetes have not been extensively isolated and screened for their bioactivities. Endophytic basidiomycetes account only for $10 \%$ of the total endophytic population isolated from different plants (Rana et al. 2019). Isolation of endophytic basidiomycetes was carried out on medium supplemented with benomyl. Benomyl is a fungicide which interferes in the process of mitosis in fungi by targeting microtubules. It can act as a selective agent for the isolation of basidiomycetes as some strains possess a mutation in the $\beta 1$ - tubulin gene which makes them resistant to benomyl (Matsuo et al. 1999). Even though the medium used in isolation is recommended for the basidiomycetes, members of the order pleosporales, to which Alternaria belongs, are reported to show resistance against benomyl (Summerbell 1993). This could account for a high number of endophytic Alternaria sp. obtained in the present study. Preliminary screening for determining antidiabetic potential was carried out by the ability of the isolates to produce AGI. On the basis of in-vitro AGI activity, a fungal culture Sch1 identified to be Schizophyllum commune was selected. S. commune, a basidiomycete commonly known as split gill fungus, belongs to the family schizophyllaceae of the class agaricomycetes. It is an edible mushroom consumed in different parts of the world mainly in Mexico, Peninsular Malaysia, Nagaland (India), and the Republic of the Congo (Guzmán 2008; Lee et al. 2009; Tanti et al. 2011; Kamalebo et al. 2018). It has also been reported as an endophyte from various plants viz. Tectona grandis, Musa spp., and Cannabis sativa by various researchers (Chareprasert et al. 2006; Assunçao et al. 2010; Qadri et al. 2013). A survey of literature has revealed the traditional use of $S$. commune as therapeutic for headache, indigestion, inflammation, intestinal pain, obesity, rheumatism, and weakness (Guzmán 2008; Kamalebo et al. 2018). In addition, S. commune also exhibits antioxidant, antiviral, antitumor, and immunomodulating activities (Ooi and Liu 2000; Klaus et al. 2011). Although $\alpha$-glucosidase inhibitors from different endophytic fungi have been reported (Ramdanis et al. 2012; Singh and Kaur 2016; Kaur et al. 2019) to the best of our knowledge this is the first study revealing the AGI activity of endophytic $S$. commune.

As the culture exhibited in-vitro antidiabetic activity, its in-vivo effect was also studied in STZ induced diabetic rats. STZ is the most commonly used drug to induce diabetes in experimental animals. GLUT-2 transporter in the plasma membrane transports STZ to the pancreatic beta cells. Accumulation of STZ in beta cells results in cell necrosis by DNA alkylating activity which in turn reduces the synthesis and release of insulin, responsible for hyperglycemia (Lenzen 2008). Oral administration of $S$. commune extract displayed significant improvement in glucose homeostasis of diabetic rats. The lowering in blood glucose level could be due to the AGI potential of S. commune extract. $\alpha$-Glucosidase is a carbohydrate hydrolysing enzyme present in the brush border of the intestine. Carbohydrate hydrolysing activity of this enzyme is mainly responsible for postprandial hyperglycemia. $\alpha$-Glucosidase inhibitors such as acarbose and voglibose help to reduce the blood glucose level by expanding the carbohydrate absorption duration and have been used since a long time for the treatment of diabetes mellitus (Van De Laar et al. 2005).

Another clinical feature of diabetes mellitus is body weight loss, due to tissue wasting caused by poor glycemic control which results in increased protein and fat metabolism in diabetic rats (Adeoye et al. 2017). A significant increase in the body weight of diabetic rats treated with fungal extract was recorded at the end of the experimental period. Diabetes mellitus is also characterized by dyslipidemia which accounts for elevated levels of TC, TG, LDL, and lower level of HDL (Bhowmik et al. 2018.) In diabetic patients, dyslipidemia is a major cause of cardiovascular disease. There are several factors that are responsible for disturbed lipid profile in diabetic patients viz. effect of insulin on the production of apoprotein in the liver, lipoprotein lipase regulation, activity of cholesteryl ester transfer protein, and action of insulin on muscle and adipose (Goldberg 2001). Treatment with $S$. commune extract showed significant improvement in lipid profile. Diabetic nephropathy is another major complication of diabetes mellitus. Among diabetic patients, approximately $40 \%$ require dialysis on a regular basis. Diabetes associated glomerular damage results in chronic renal insufficiency (Patschan and Müller 2016). Creatinine, BUN, potassium, and FeNa have been used as markers of kidney performance (Gowda et al. 2010). A significant increase in these parameters was documented in untreated diabetic rats compared with normal control. This could be the result of kidney damage caused by diabetes. Diabetic rats treated with S. commune extract produced significant improvement in kidney parameters level after 14 days experimental period.

It has been recognized that oxidative stress plays a crucial role in the pathogenesis of diabetes related vasculopathy, retinopathy, neuropathy, and nephropathy along with gastrointestinal complications. The natural antioxidant defence system is also depressed when acute elevation in glucose level occurs (Giugliano et al. 1996; Kashyap and Farrugia 2011). GSH (non-protein thiol) is 
a potent antioxidant existing nearly in all living cells and is used as a redox imbalance biomarker at cellular level. Disturbed GSH profile is embroiled in $\beta$-cell dysfunction along with pathogenesis of long-term diabetes assisted complications (Tiwari et al. 2013). Free radical activity has been reported to increase in diabetes mellitus. These free radicals cause lipid peroxidation which plays a vital role in atherosclerosis, aging, and late complication of diabetes mellitus. TBARS determination was performed to measure the level of lipid peroxidases (Griesmacher et al. 1995). Hyperglycemia also results in superoxide anion generation, which ultimately causes oxidation of proteins, nitration of amino acids, and initiates lipid peroxidation (Wright et al. 2006). In the present study, an imbalance in oxidative stress parameters documented in untreated diabetic control was restored significantly after treatment of the diabetic rats with S. commune extract.

Transaminases like SGPT, SGOT play an important role in the breakdown of amino acids into $\alpha$-keto acid. These enzymes are specific indicators of liver function. In hepatocyte injury, the level of these enzymes increases which enhances the rate of gluconeogenesis and ketogenesis (Onaolapo and Onaolapo 2012). Another enzyme ALP can also be used to monitor liver functioning. Diabetes is responsible for a large number of liver disorders viz. elevated liver enzymes, hepatocellular carcinoma, fatty liver disease, cirrhosis, and acute liver failure (Tolman et al. 2007). In this study diabetic rats treated with $S$. commune extract revealed a significant reduction in the level of SGOT, SGPT, and ALP. It is evident from the results obtained that the administration of $S$. commune extract significantly exerted a beneficial effect on all the observed biochemical parameters.

Phytochemical analysis to detect the nature of the compounds revealed the presence of phenolic and terpenoids which could be responsible for the observed effect. Phenolic and terpenoid compounds have been reported to manifest antihyperglycemic and antioxidant effects in diabetic rats (Gandhi et al. 2011; Germoush et al. 2020). Reports of antidiabetic potential of various basidiomycetes and compounds produced by them are available in literature. Phenolic compounds with AGI activity have been reported in mushrooms (Liu et al. 2012). Potent $\alpha$-glucosdiase inhibitory terpenoids were characterized from submerged grown culture of Inonotus obliquus (Ying et al. 2014). Different species of Ganoderma are reported to produce various types of terpenoids and polysaccharides with the ability to cure diabetes and insulin resistance (Wińska et al. 2019). $\beta$-Glucans and oligosaccharides isolated from Agaricus blazei were found to exert hypoglycemic effect in diabetic rats (Kim et al. 2005). Antidiabetic $\beta$-glucans and polysaccharide-peptide have been isolated from species of Pleurotus (Kanagasabapathy et al. 2012;
Chen et al. 2015). Although various basidiomycetes have been reported to exhibit antidiabetic activity (Jeong et al. 2010; Ng et al. 2015), this is the first report highlighting the therapeutic potential of S. commune in the management of diabetes.

It can be concluded that $S$. commune can be exploited as a source of compounds that can have potential in the management of diabetes. The study also reveals the importance of endophytic basidiomycetes as sources of bioactive metabolites.

\section{Abbreviations \\ STZ: Streptozotocin; PDA: Potato dextrose agar; AGI: a-Glucosidase inhibi- tory; p-NPG: p-Nitrophenyl-alpha-D-glucopyranoside; BUN: Blood urea nitrogen; FeNa: Fractional excretion of sodium; SGPT: Serum glutamic pyruvic transaminase; SGOT: Serum glutamic-oxaloacetic transaminase; ALP: Alkaline phosphatase; GSH: Reduced glutathione; TBARS: Thiobarbituric acid reactive substances; TC: Total cholesterol; TG: Triglyceride; HDL: High density lipopro- tein; LDL: Low-density lipoprotein; DTNB: 5,5-Dithio-bis-(2-nitro benzoic acid); NBT: Nitro blue tetrazolium chloride.}

\section{Acknowledgements}

Authors are thankful to Council of Scientific and Industrial Research (CSIR), New Delhi, India for providing financial support.

\section{Authors' contributions}

AK and RB designed the experiments and analysed the contents. AS, RK, JK and SG performed the experiments and analysed the data. All authors read and approved the final manuscript.

\section{Funding}

Not applicable.

\section{Availability of data and materials}

All data generated or analysed during this study are included in this published article.

\section{Declarations}

\section{Ethics approval and consent to participate}

Animal experiment protocol (226/CPCSEA 2017/03) was duly approved by Institutional Animal Ethics Committee (IAEC) of Guru Nanak Dev University, Amritsar, Punjab. All the experiments were conducted in accordance with the guidelines established by Committee for the Purpose of Control and Supervision of Experiments on Animals (CPCSEA), Ministry of Environment, Forests and Climate Change, Government of India.

\section{Consent for publication}

Not applicable.

\section{Competing interests}

The authors declare that they have no competing interests.

\author{
Author details \\ ${ }^{1}$ Department of Microbiology, Guru Nanak Dev University, Amritsar, Punjab \\ 143005, India. ${ }^{2}$ Department of Pharmaceutical Sciences, Guru Nanak Dev \\ University, Amritsar, Punjab 143005, India.
}

Received: 23 December 2020 Accepted: 9 April 2021

Published online: 21 April 2021 


\section{References}

Adeoye AT, Oyagbemi AA, Adedapo AD, Omobowale TO, Ayodele AE, Adedapo AA (2017) Antidiabetic and antioxidant activities of the methanol leaf extract of Vernonia amygdalina in alloxan-induced diabetes in Wistar rats. J Med Plants Econ Dev 1:1-12

Assunção MMC, Cavalcanti MDQ, Menezes M (2010) Schizophyllum commune isolated from banana leaves (Musa spp.), as endophytic fungi, in Pernambuco. Brazil Agrotrópica 22:67-70

Batool R, Khan MR, Sajid M, Ali S, Zahra Z (2019) Estimation of phytochemical constituents and in vitro antioxidant potencies of Brachychiton populneus (Schott \& Endl.) R. Br. BMC Chem 13:1-15

Beutler E, Duron O, Kelly BM (1963) Improved method for the determination of blood glutathione. J Lab Clin Med 61:882-888

Bhowmik B, Siddiquee T, Mujumder A, Afsana F, Ahmed T, Mdala IA, Moreira DV, Cristina N, Khan AKA, Hussain A, Holmboe-Ottesen G (2018) Serum lipid profile and its association with diabetes and prediabetes in a rural Bangladeshi population. Int J Environ Res Public Health 15:1-12

Ceriello A (2005) Postprandial hyperglycemia and diabetes complications: is it time to treat? Diabetes 54:1-7

Chareprasert S, Piapukiew J, Thienhirun S, Whalley AJ, Sihanonth P (2006) Endophytic fungi of teak leaves Tectona grandis $\mathrm{L}$. and rain tree leaves Samanea saman Merr. World J Microbiol Biotechnol 22:481-486

Chaudhury A, Duvoor C, Reddy Dendi VS, Kraleti S, Chada A, Ravilla R, Marco A, Shekhawat NS, Montales MT, Kuriakose K, Sasapu A (2017) Clinical review of antidiabetic drugs: implications for type 2 diabetes mellitus management. Front Endocrinol 8:6

Chen RR, Liu ZK, Liu F, Ng TB (2015) Antihyperglycaemic mechanisms of an aceteoside polymer from rose flowers and a polysaccharide-protein complex from abalone mushroom. Nat Prod Res 29:558-561

Cho N, Shaw JE, Karuranga S, Huang Y, da Rocha Fernandes JD, Ohlrogge AW, Malanda B (2018) IDF Diabetes Atlas: Global estimates of diabetes prevalence for 2017 and projections for 2045. Diabetes res Clin Pract 138:271-281

Clements RS Jr, Bell DS (1985) Complications of diabetes: prevalence, detection, current treatment, and prognosis. Am J Med 79:2-7

Gandhi GR, Ignacimuthu S, Paulraj MG (2011) Solanum torvum Swartz. fruit containing phenolic compounds shows antidiabetic and antioxidant effects in streptozotocin induced diabetic rats. Food Chem Toxicol 49:2725-2733

Gavin JR III (2001) Pathophysiologic mechanisms of postprandial hyperglycemia. Am J Cardiol 88:4-8

Germoush MO, Elgebaly HA, Hassan S, Kamel EM, Bin-Jumah M, Mahmoud AM (2020) Consumption of terpenoids-Rich Padina pavonia extract attenuates hyperglycemia, insulin resistance and oxidative stress, and upregulates PPARy in a rat model of type 2 diabetes. Antioxidants 9:1-24

Giugliano D, Ceriello A, Paolisso G (1996) Oxidative stress and diabetic vascular complications. Diabetes Care 19:257-267

Goldberg IJ (2001) Diabetic dyslipidemia: causes and consequences. J Clin Endocrinol Metab 86:965-971

Gowda S, Desai PB, Kulkarni SS, Hull W, Math AA, Vernekar SN (2010) Markers of renal function tests. N Am J Med Sci 2:170-173

Griesmacher A, Kindhauser M, Andert SE, Schreiner W, Toma C, Knoebl P, Pietschmann P, Prager R, Schnack C, Schemthaner G, Mueller MM (1995) Enhanced serum levels of thiobarbituric-acid-reactive substances in diabetes mellitus. Am J Med 98:469-475

Guzmán G (2008) Diversity and use of traditional Mexican medicinal fungi. A review. Int J Med Mushrooms 10:209-217

Jeong SC, Jeong YT, Yang BK, Islam R, Koyyalamudi SR, Pang G, Cho KY, Song CH (2010) White button mushroom (Agaricus bisporus) lowers blood glucose and cholesterol levels in diabetic and hypercholesterolemic rats. Nutr Res 30:49-56

Kamalebo HM, Malale HNSW, Ndabaga CM, Degreef J, De Kesel A (2018) Uses and importance of wild fungi: traditional knowledge from the Tshopo province in the Democratic Republic of the Congo. J Ethnobiol Ethnomed 14:1-12

Kanagasabapathy G, Kuppusamy UR, Abd Malek SN, Abdulla MA, Chua KH, Sabaratnam V (2012) Glucan-rich polysaccharides from Pleurotus sajorcaju (Fr.) Singer prevents glucose intolerance, insulin resistance and inflammation in C57BL/6J mice fed a high-fat diet. BMC Complement Altern Med 12:1-9
Kashyap P, Farrugia G (2011) Oxidative stress: key player in gastrointestinal complications of diabetes. Neurogastroenterol Motil 23:111-114

Katoch M, Singh A, Singh G, Wazir P, Kumar R (2017) Phylogeny, antimicrobial, antioxidant and enzyme-producing potential of fungal endophytes found in Viola odorata. Ann Microbiol 67:529-540

Kaul S, Gupta S, Ahmed M, Dhar MK (2012) Endophytic fungi from medicinal plants: a treasure hunt for bioactive metabolites. Phytochem Rev 11:487-505

Kaur J, Sharma A, Sharma M, Manhas RK, Kaur S, Kaur A (2019) Effect of a-glycosidase inhibitors from endophytic fungus Alternaria destruens on survival and development of insect pest Spodoptera litura Fab. and fungal phytopathogens. Sci Rep 9:1-13

Kaur R, Kaur J, Kaur M, Kalotra V, Chadha P, Kaur A, Kaur A (2020) An endophytic Penicillium oxalicum isolated from Citrus limon possesses antioxidant and genoprotective potential. J Appl Microbiol 128:1400-1413

Kim YW, Kim KH, Choi HJ, Lee DS (2005) Anti-diabetic activity of $\beta$-glucans and their enzymatically hydrolyzed oligosaccharides from Agaricus blazei. Biotechnol Lett 27:483-487

Klaus A, Kozarski M, Niksic M, Jakovljevic D, Todorovic N, Van Griensven LJ (2011) Antioxidative activities and chemical characterization of polysaccharides extracted from the basidiomycete Schizophyllum commune. LWT- Food Sci Technol 44:2005-2011

Lee SS, Chang YS, Noraswati MNR (2009) Utilization of macrofungi by some indigenous communities for food and medicine in Peninsular Malaysia. For Ecol Manag 257:2062-2065

Lenzen S (2008) The mechanisms of alloxan-and streptozotocin-induced diabetes. Diabetologia 51:216-226

Liu YT, Sun J, Luo ZY, Rao SQ, Su YJ, Xu RR, Yang YJ (2012) Chemical composition of five wild edible mushrooms collected from Southwest China and their antihyperglycemic and antioxidant activity. Food Chem Toxicol 50:1238-1244

Martin R, Gazis R, Skaltsas D, Chaverri P, Hibbett D (2015) Unexpected diversity of basidiomycetous endophytes in sapwood and leaves of Hevea. Mycologia 107:284-297

Matsuo T, Yamamoto Y, Muraguchi H, Kamada T (1999) Effects of amino-acid substitutions in $\beta$ tubulin on benomyl sensitivity and microtubule functions in Coprinus cinereus. Mycoscience 40:241-249

Ng SH, Mohd Zain MS, Zakaria F, Wan Ishak WR, Wan Ahmad WAN (2015) Hypoglycemic and antidiabetic effect of Pleurotus sajor-caju aqueous extract in normal and streptozotocin-induced diabetic rats. Biomed Res Int 2015:1-8

Niehaus WG Jr, Samuelsson B (1968) Formation of malonaldehyde from phospholipid arachidonate during microsomal lipid peroxidation. Eur J Biochem 6:126-130

Onaolapo A, Onaolapo O (2012) Ocimum Gratissimum Linn causes dose dependent hepatotoxicity in streptozotocin-induced diabetic Wistar rats. Open Access Maced J Med Sci 5:17-25

Ooi VEC, Liu F (2000) Immunomodulation and anti-cancer activity of polysaccharide-protein complexes. Curr Med Chem 7:715-729

Oses R, Valenzuela S, Freer J, Sanfuentes E, Rodriguez J (2008) Fungal endophytes in xylem of healthy Chilean trees and their possible role in early wood decay. Fungal Divers 33:77-86

Patschan D, Müller GA (2016) Acute kidney injury in diabetes mellitus. Int J Nephrol 2016:1-7

Petrini O (1991) Fungal endophytes of tree leaves. In: Andrews JH, Hirano SS (eds) Microbial ecology of leaves. Springer, New York

Puri SC, Nazir A, Chawla R, Arora R, Riyaz-ul-Hasan S, Amna T, Ahmed B, Verma V, Singh S, Sagar R, Sharma A (2006) The endophytic fungus Trametes hirsuta as a novel alternative source of podophyllotoxin and related aryl tetralin lignans. J Biotechnol 122:494-510

Qadri M, Johri S, Shah BA, Khajuria A, Sidiq T, Lattoo SK, Abdin MZ, RiyazUl-Hassan S (2013) Identification and bioactive potential of endophytic fungi isolated from selected plants of the Western Himalayas. Springerplus 2:8

Ramdanis R, Soemiati A, Munim A (2012) Isolation and a-Glucosidase inhibitory activity of endophytic fungi from mahogany (Swietenia macrophylla King) seeds. Int J Med Arom Plants 2:447-452

Rana KL, Kour D, Sheikh I, Yadav N, Yadav AN, Kumar V, Singh BP, Dhaliwal HS, Saxena AK (2019) Biodiversity of endophytic fungi from diverse niches and their biotechnological applications. In: Singh BP (ed) Advances in endophytic fungal research. Springer, Cham 
Singh B, Kaur A (2016) Antidiabetic potential of a peptide isolated from an endophytic Aspergillus awamori. J Appl Microbiol 120:301-311

Strobel G, Daisy B (2003) Bioprospecting for microbial endophytes and their natural products. Microbiol Mol Biol Rev 67:491-502

Summerbell RC (1993) The benomyl test as a fundamental diagnostic method for medical mycology. J Clin Microbiol 31:572-577

Tanti B, Lisha G, Chandra SG (2011) Wild edible fungal resources used by ethnic tribes of Nagaland, India. Indian J Tradit Knowl 10:512-515

Tiwari BK, Pandey KB, Abidi AB, Rizvi SI (2013) Markers of oxidative stress during diabetes mellitus. J Biomark 2013:1-8

Tolman KG, Fonseca V, Dalpiaz A, Tan MH (2007) Spectrum of liver disease in type 2 diabetes and management of patients with diabetes and liver disease. Diabetes Care 30:734-743

Van De Laar FA, Lucassen PL, Akkermans RP, Van De Lisdonk EH, Rutten GE, Van Weel C (2005) a-Glucosidase inhibitors for patients with type 2 diabetes: results from a Cochrane systematic review and meta-analysis. Diabetes Care 28:154-163

Waksmundzka-Hajnos M, Sherma J, Kowalska T (eds) (2008) Thin layer chromatography in phytochemistry. CRC Press, Boca Raton

Waller F, Achatz B, Baltruschat H, Fodor J, Becker K, Fischer M, Heier T, Hückelhoven R, Neumann C, Von Wettstein D, Franken P (2005) The endophytic fungus Piriformospora indica reprograms barley to salt-stress tolerance, disease resistance, and higher yield. Proc Natl Acad Sci 102:13386-13391
Wang HD, Pagano PJ, Du Y, Cayatte AJ, Quinn MT, Brecher P, Cohen RA (1998) Superoxide anion from the adventitia of the rat thoracic aorta inactivates nitric oxide. Circ Res 82:810-818

Warnick GR, Knopp RH, Fitzpatrick V, Branson L (1990) Estimating low-density lipoprotein cholesterol by the Friedewald equation is adequate for classifying patients on the basis of nationally recommended cutpoints. Clin Chem 36:15-19

Wińska K, Mączka W, Gabryelska K, Grabarczyk M (2019) Mushrooms of the genus Ganoderma used to treat diabetes and insulin resistance. Molecules 24:4075

Wright E Jr, Scism-Bacon JL, Glass LC (2006) Oxidative stress in type 2 diabetes: the role of fasting and postprandial glycaemia. Int J Clin Pract 60:308-314

Ying YM, Zhang LY, Zhang X, Bai HB, Liang DE, Ma LF, Shan WG, Zhan ZJ (2014) Terpenoids with alpha-glucosidase inhibitory activity from the submerged culture of Inonotus obliquus. Phytochemistry 108:171-176

\section{Publisher's Note}

Springer Nature remains neutral with regard to jurisdictional claims in published maps and institutional affiliations.

\section{Submit your manuscript to a SpringerOpen ${ }^{\circ}$ journal and benefit from:}

- Convenient online submission

- Rigorous peer review

- Open access: articles freely available online

- High visibility within the field

- Retaining the copyright to your article

Submit your next manuscript at $\boldsymbol{\nabla}$ springeropen.com 